\title{
Quarter-mile walk test sensitive to training-induced fitness changes
}

Papini, Gabriele; Carder, Chandrie; Lightfoot, Courtney J.; Kubis, Hans-Peter; Bonomi, Alberto G.

\section{Journal of Sports Medicine and Physical Fitness}

\author{
DOI: \\ 10.23736/S0022-4707.19.09445-3
}

Published: 01/11/2019

Peer reviewed version

Cyswllt i'r cyhoeddiad / Link to publication

Dyfyniad o'r fersiwn a gyhoeddwyd / Citation for published version (APA):

Papini, G., Carder, C., Lightfoot, C. J., Kubis, H-P., \& Bonomi, A. G. (2019). Quarter-mile walk test sensitive to training-induced fitness changes. Journal of Sports Medicine and Physical Fitness, 59(11), 1820-7. https://doi.org/10.23736/S0022-4707.19.09445-3

\footnotetext{
Hawliau Cyffredinol / General rights

Copyright and moral rights for the publications made accessible in the public portal are retained by the authors and/or other copyright owners and it is a condition of accessing publications that users recognise and abide by the legal requirements associated with these rights.

- Users may download and print one copy of any publication from the public portal for the purpose of private study or research.

- You may not further distribute the material or use it for any profit-making activity or commercial gain

- You may freely distribute the URL identifying the publication in the public portal ?
}

Take down policy

If you believe that this document breaches copyright please contact us providing details, and we will remove access to the work immediately and investigate your claim. 


\section{Quarter-mile walk test sensitive to training-induced fitness changes}

Journal: The Journal of Sports Medicine and Physical Fitness

Paper code: J Sports Med Phys Fitness-9445

Submission date: October 23, 2018

Article type: Original Article

Files:

1. Reply letter to comments on the manuscript

Version: 1

Description:

File format: application/vnd.openxmlformats-officedocument.wordprocessingml.document

2. Manuscript

Version: 4

Description: Manuscript

File format: application/vnd.openxmlformats-officedocument.wordprocessingml.document

3. Figures 1

Version: 1

Description: Figure 1

File format: image/tiff

4. Figures 2

Version: 1

Description: Figure 2

File format: image/tiff

5. Figures 3

Version: 1

Description: Fig3

File format: image/tiff 
Dear Editor Prof. Alberto Oliaro,

Thank you to give us the opportunity to improve our manuscript. Quarter-mile walk test sensitive to training-induced fitness changes registered under no. J Sports Med Phys Fitness- 9445.

We took on board the comment of the reviewer and have considerably re-written the manuscript. We have done so asking a second native speaker to critically review our work and proofread it. As Mrs. Courtney Lightfoot, BSc, MSc has extensively worked on the manuscript we would like to add her to the list of authors. Additionally, we made some more changes to the author list since Mrrs. Chandrie Cox, BSc, MSc would prefer to use her married name Carder. Hope this will not be a problern. Now we have two native speakers, Mrs. Lightfoot from the UK and Mrs. Carder from the USA, having had a close look to the scientific style and English grammar. We hope that the reviewer will be pleased with or effort.

Best regards,

Francesco Sartor, Ph.D.

Senior Scientist

Patient Care \& Measurements

Philips Research

Philips Electronics Nederland B.Y. ATC 341011 , P. OSDX WBG1, 5856AE Eindhoven, The Netherlands Tel +31(0)615509627, Email: francesco.sartor@philips.coms

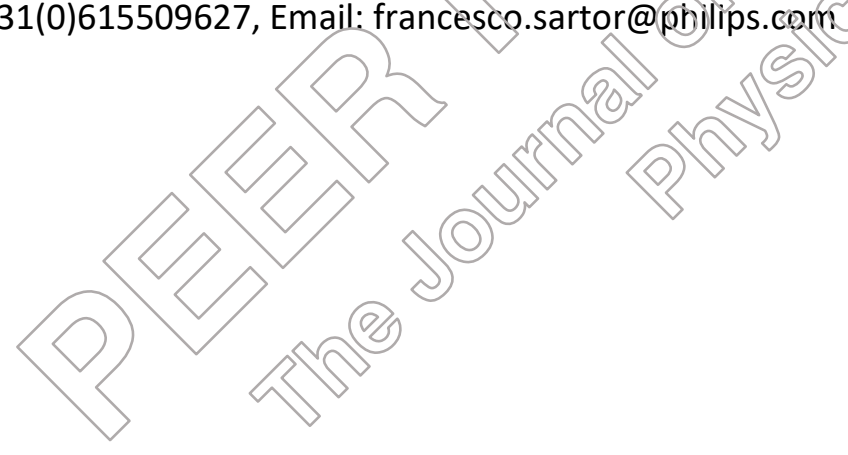




\section{Gabriele B. PAPINI ${ }^{1,2}$, Chandrie CARDER ${ }^{2,3}$, Courtney J. LIGHTFOOT ${ }^{4}$, Hans-Peter KUBIS $^{3}$, Alberto G. BONOMI ${ }^{2}$, Francesco SARTOR ${ }^{2,3 *}$}

\footnotetext{
${ }^{1}$ Department of Electrical Engineering, Eindhoven University of Technolegy, Eindhoven, The Netherlands, ${ }^{2}$ Department of Personal Health, Philips Research, Eindhoven, The Netherlands, ${ }^{3}$ School of Sport, Health and exercise Sciences, Bangor University, The United Kingdom, Department of Health Sciences, University of Leicester, The United Kingdorm
}

*Corresponding author: Francesco Sartor, Department of Personal Heain, Philips Research, High Tech Campus 34, 5.005-1, P 0. BoxWB61, 5656AE, Eindhosen, The Netherlands. Email: francesco.sartor@philips.com.

BACKGROUND Cardiorespiratory fitness (CRF) is an important aspect of the overall health of an individual and its monitoring must be promoted in the general population. Thus, the aim of the study was to cross-validate and improve CRF estimation based on quartermile Rockport Fitness Walking Test.

METHODS: Thirty participants $(31.4 \pm 7.99$ years) were randomized in either a four-week aerobic training group (10 men and 10 women) or a control group (eight men and two women). $\mathrm{CRF}$ was assessed via $\mathrm{VO}_{2}$ max test and estimated via quarter-mile Rockport Fitness and Ebbeling treadmill tests, before and after the training intervention. The original quarter-mile Rockport $\mathrm{VO}_{2}$ max estimation was found to greatly overestimate CRF by $22 \mathrm{ml}$ 
$\cdot \mathrm{kg}^{-1} \cdot \min ^{-1}$. When its coefficient was updated according to our data, it largely improved (by $6.8 \mathrm{ml} \cdot \mathrm{kg}^{-1} \cdot \mathrm{min}^{-1}$ ). Furthermore, a new-algorithm for predicting $\mathrm{VO}_{2}$ max was designed using multi-linear regression analysis.

RESULTS: The original quarter-mile Rockport Fitness Walking Test was not sensitive to CRF changes. It showed changes in $\mathrm{VO}_{2}$ max, which were significantly different from the actual observed changes $(-1.1 \pm 4.08$ vs. $1.61 \pm 2.84, p=0.02$, respectively). Ebbeing treadmill test appeared to systematically overestimate CRF changes. Our new-algorithm showed improved sensitivity for detecting CRF changes and stability.

CONCLUSIONS: The original quarter-mile Rockport Fitness Walking equation for predicting $\mathrm{VO}_{2}$ max was neither accurate nor sensitive to changes in CRF. most likely due to cardiovascular drift. Our new-algorithm, based on the same brisk walking test, can provide a more accurate estimate of CRF, which is also sensitive to Vornax changes, in a broad age range (18 to 50 years).

Key words: Exercise testing; Cardiorespiratory fitness; Walking; $\mathrm{VO}_{2}$ max

\section{Introduction}

Cardiorespiratory fitness (CRF) is thie ability ar the circulatory, respiratory, and muscular systems to supply oxygen to the body during sustained physical activity ${ }^{1}$. CRF has been shown to piay a roleg protecting against all-cause and cardiovascular disease (CVD) mortality in both men and women ${ }^{2}$. Moderate to high levels of CRF have been suggested to lower the increased risk of mortality associated with obesity ${ }^{3}$. It is clear from previous research that $\mathrm{CRF}$ is an important aspect in the overall health of an individual. In previous years, our laboratory has reviewed and developed a number of submaximal CRF assessment protocols ${ }^{4-6}$, that could be performed in a variety of settings by a diverse population. As noted by Sartor et al. ${ }^{6}$, "when changes over time in $\mathrm{VO}_{2}$ max need to be monitored, it is important that the submaximal test is precise". Nonetheless, a submaximal test that is stable over 
multiple tests could be insensitive to changes. Therefore, the purpose of this study was to investigate a submaximal test that can not only be performed by a large and diverse population, but is also accurate, precise, and sensitive to exercise-induced CRF changes.

In order for a submaximal test to be able to be performed by a majority of the population, the means by which the test is conducted needs to be commonplace throughout society. Walking is an action that is conducted by the general population every day, making it a widely accessible and performable means by which to be tested submaximally. Walking itself does not require specialist exercise equipment such as a cycle ergometer or step, and thie intensity can be easily altered by increasing or decreasing speed. A treadmill cân be used, if desired, but walking can easily be performed in numerous locations and settings. Therefore, walking was considered to be the ideal modality for testing the general Gopulation. Walking submaximal $\mathrm{VO}_{2}$ max tests have been of interest in the healin comminity for a number of years ${ }^{6}$. A self-paced walking test has previousty been developed, sut it focuses solely on an elderly population and is not suitable for those with higher functional abilities ${ }^{7,8}$. Thus, having a submaximal $\mathrm{VO}_{2}$ nax test that can serye a wider fange of ability and age would be preferable. In an attempt to further improve upon Copper's field test and make it more adaptable to a wider popylation, Kline et ${ }^{9}$ developed a protocol to predict $\mathrm{VO}_{2}$ max based upon a onemile walk around atrack, also known as the Rockport Fitness Walking Test ${ }^{9}$. The Rockport Fitness Walking Test uses variables including weight, age, sex, track walking time, and the heart rate during the fourth quarter of the mile. This method proved to be reliable in both men and women between 30 and 69 years of age. The Rockport Fitness Walking Test was further evaluated and modified to create a test that could be performed in a shorter amount of time ${ }^{10}$. The quarter-mile (approximately 400 meters) Rockport Fitness Walking Test appears to be an ideal option to test a large and diverse population in a way which does not require the use of exercise equipment. It predicts $\mathrm{VO}_{2}$ max through the use of sex, age, weight, end exercise heart 
rate, and the time taken to complete a quarter of a mile. This prediction equation was originally developed through the testing of male and female college-aged students. However, this test has not yet been validated on a wider spectrum of the population, leaving the question of its versatility unanswered. Moreover, the quarter-mile - walking test was not tested for precision and sensitivity to fitness changes following the introduction of an exercise programme. The purpose of this study was to validate and develop the equation for the quarter-mile walking test, making it suitable for the general population between the ages of 18 and 50 years and sensitive to training-induced fitness changes.

\section{Materials and methods}

\section{Participants}

This study was a single-blind randomized controlled design. Menand women between the ages of 18 and 50 were recruited as participants fothis study through posters on the premises of the High Tech Campus and then contacied via e-naigl. Participants were excluded if they suffered from any chronic disease or cognitive impairments, took medications affecting hormonal and inetabolic systems, or werepregnant. Screening for these exclusion factors was done using $A \mathrm{HA} / \mathrm{ACSM}$ screening tools ${ }^{11}$. Thirty participants were recruited for this study (18 men and 12 women ${ }^{1}$. The a-priori sample size calculation based on George et al. ${ }^{10}$ results $\left(r^{2}=0.68 ;\right.$ effect size $=2.125$, statistical power $=0.8$, number of predictors $=4$, and $\mathrm{p}$ value $=0.05)$, indicated that a total of 12 participants would have been sufficient, to create a prediction model. However, due to the added intention to investigate the sensitivity to traininginduced changes, it was deemed appropriate to increase the sample size to 20 in the training group and 10 in the control group. Thus, 20 participants (10 men and 10 women) were randomly assigned to the training group through the use of an online randomizer (http://www.randomization.com) and 10 participants were randomly assigned to the control 
group ( 8 men and 2 women). Prior to testing, participants were provided with an information sheet detailing the study and were required to provide written informed consent to participate in the study. Submaximal testing and exercise training were conducted at Philips Research Laboratories in Eindhoven, The Netherlands. $\mathrm{VO}_{2} \max$ testing was conducted at Máxima Medical Center in Veldhoven, The Netherlands. This study was approved by the Internal Committee of Biomedical Experiments of Philips Research.

\section{Submaximal Testing}

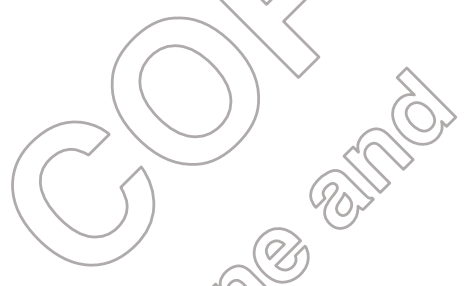

Each participant attended the Philips Research laboratory for submaximal testing on two separate occasions. In each testing session, the same protocol was followed. The participant was asked to come dressed in comfortable sporting clothing for exercisennd having fasted for the previous two hours from food and caffeine. Upon armival, the porticipant was seated and informed of the protocol. The participant's heightoyas measured, and their body weight and composition were assessed using a digitai weighingsoscale that also estimated body fat percentage via bic-electrical impedange (BC-533,Tanita, Amsterdam, The Netherlands). The participant was then given a heart rate chest strap to wear (RS800 CX, Polar Electro, Almere, The Netherhands) in order to monitor heart rate and inter-beat-intervals. The device was started and the participant sat still in an upright position for 10 minutes in order to obtain a resting heart rate (HRR). During this time, the light was switched off to help the participant relax. Following the 10 minutes' rest, the participant began the first submaximal test. For the first submaximal test, the Ebbeling treadmill test was performed ${ }^{11}$. The participant walked on the treadmill (Kettler Marathon TX1, Ense-Parsit, Germany) for four minutes at a speed that raised his heart rate between 50 and $75 \%$ of the maximum heart rate. Once this was achieved, the speed was maintained and the incline was increased to 5\%. The participant then walked for a 
further four minutes, or an additional five minutes if the heart rate was not stable in the final two minutes.

Ebbeling prediction equation is:

$\dot{\mathrm{V}}_{\text {O2max }}=15.1+21.8 \cdot$ Speed $[\mathrm{mph}]-0.327 \cdot \mathrm{HR}[\mathrm{bpm}]-0.263 \cdot$ Speed $[\mathrm{mph}] \cdot$ Age $[$ years $]+0.00504 \cdot \mathrm{HR}[\mathrm{bpm}] \cdot$ Age $[$ years $]+5.98 \cdot \operatorname{Sex}[0=$ women; $1=$ men $]$.

At the end of the test, the participant rested until their heart rate was, back to resting levels. Resting HR levels were defined as $5 \%$ of participants heart rate reserve (neart rate max -heart rate rest). Following this, the participant was taken to the start of the second submaximal test which was the quarter-mile walking test. The test was conducted outdGrs on the High Tech Campus premises. The participant was instructed to maintain a brisk walk from the start to the finish of the quarter-mile. The distance ywas assessed at first by means of G.P.S. system and then subsequently measured using a 60-meter-long measuring tape (Stanley, Born, The Netherlands).

The previously published "old" quarter-mile Rockport Fitness Walking Test prediction equationis.

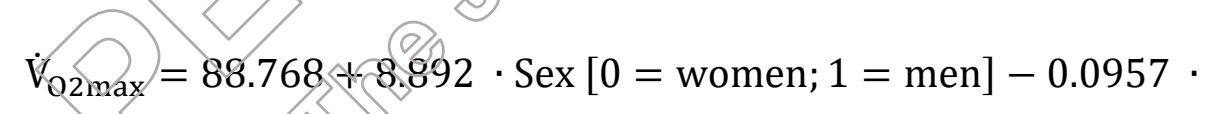

Body Weight [pounds] $-1.4537 \cdot$ Walk Time [minutes] $-0.1194 \cdot \mathrm{HR}[\mathrm{bpm}]$.

\section{[Eq.2]}

At the end of the quarter-mile walking test, the heart rate monitor was stopped. Both the walk time and the heart rate on cessation of the test were recorded. This submaximal test was conducted at the beginning of the study and at the end of the four-week intervention. 


\section{Maximal Testing}

Each participant was asked to attend the Sportmax Performance Centre of the Máxima Medical Center for a cycle ergometer (Lode, Excalibur, Groningen, the Netherlands) $\mathrm{VO}_{2}$ max test following the pre and post submaximal tests. The maximal test was conducted at least 24 hours after the submaximal test. The participant came dressed in comfortable sporting clothes having fasted for the previous two hours from food and caffeine, similar to the submaximal sessions. Upon arrival, a member of the research team informed the participant of the protocoffor the $\mathrm{VO}_{2}$ max prior to conducting the maximal test. Participants' weight and height were measured. The participant was then seated on the cycle ergorneter and set up for the $\mathrm{VO}_{2}$ max. The $\mathrm{VO}_{2} \max$ was measured using the Oxycon system (Oxycon Pro Mietabolic Cart, Carefusion, California, USA). Calibration of the Oxycon system was executed before each test according to the manufacturer's protocol. The test was conducted by trained cardiac nurses at the Sportmax Performance Centre. The nurses calculated a ramp procedure following ACSM guidelines ${ }^{12}$ which enabled the estivnated maximum wattage to be reached around 10 minutes. After a two minute warm up at a light iniensity, the test began. The load on the cycle ergometer progressively increased every six seconds according to the protocol selected by the nurse. Encouragenent was provided to the participant to help them cycle until complete exhaustion. The test ended once the participant could no longer maintain a pedalling cadence above 60 rpm. Aiter completing a three minute cool down, the participant was allowed to stop. Criteria used in this study to verify maximum oxygen uptake, except for blood lactate which was not measured, are described in Sartor et al. ${ }^{6}$.

\section{Training Intervention}

Participants in the training group were asked to attend supervised training sessions in a gym 3-4 times per week. During the supervised training sessions, the participant wore a Polar heart 
rate monitor chest strap. Each of the 20 participants in the training group had an individual training program designed based on their age, sex, and the results from their $\mathrm{VO}_{2}$ max test. The training programs were designed according to the recommended frequency, intensity, time, and type (FITT) framework outlined in Table 7.4 of the American College of Sports Medicine (ACSM) ${ }^{12}$ to improve CRF and thus $\mathrm{VO}_{2}$ max performance. During each training session, each participant was given a target heart rate to aim for (i.e., around $50.7 \pm 18.9 \%$ of their heart rate reserve for the first two weeks, and $58.0 \pm 11.4 \%$ for the last two reeks of intervention on a group level). The changes in $\mathrm{VO}_{2} \max$ induced by the intervestion should allow testing of whether the quarter-mile Rockport Fitness Walking Test 10 was sensitive enough to detect such changes. Figure 1 displays the testing schedute uised.

\section{INSERT FIGURE 1 HERE}

\section{Cross-validation and algorithm improvement}

The Eq2 developed by George et al. " ${ }^{10}$, that will be referred to as "the old-algorithm" for the remainder of this paper, was validated in our stuig sample. Moreover, new coefficients were calculated based on our data to inprove tine old-algorithm. This led to a new equation referred to as the "upgated-algorithme A feed-forward multiple regression model was used to develop a new prediction equation, which we will call here the "new-algorithm". The main difference between the updated and the new algorithms stands in the predicting parameters used and consequently in the coefficients (see Eq.3 and Eq.4). These computations were performed using Matlab (version R2013b for Windows, The MathWorks Inc., Massachusetts, USA). The parameters chosen for the new-algorithm for the quarter-mile walking test were age, sex, HRR, the peak heart rate reached during the quarter-mile Rockport Fitness Walking Test normalized for the age-predicted maximum heart rate $\left(\left(\mathrm{HR}_{\text {peak }} / \mathrm{HR}_{\max }\right)^{*} 100\right)$, and the walking speed (i.e. distance divided by walking time) of the participant during the test multiplied by 
the mean heart rate during the final 30 seconds of the test (Speed*30 second HR). Agepredicted maximal HR was derived from $\left(208-0.7 \cdot\right.$ age) Tanaks's regression ${ }^{13}$. The performance of the updated- and the new-algorithms were evaluated using a 10-fold crossvalidation technique. This involved removing $10 \%$ of the total number of subjects in a ratio of 2 training groups to 1 control group, in both pre and post data, each cycle. The errors caiculated by means of this cross-validation technique determined a fairer comparisen to the errors found for the equations developed elsewhere (e.g. old-algorithm and Ebbeling test).

\section{Data Analysis}

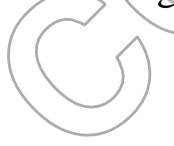

The standard errors of the estimate (SEE) were calculated to assess the accuracy of the various algorithms. A student's t-test was conducted to determine if there कuvere any significant differences between the predictions of the algorithrins fested and the observed relative $\mathrm{VO}_{2} \max$.

In order to assess the sensitivity of the updatted- and new-algorithm to changes in $\mathrm{VO}_{2} \mathrm{max}$, the change between the pre-test $\mathrm{VO}_{2}$ max data and the post-test $\mathrm{VO}_{2}$ max data were calculated. The change in the observed VO2max wasalso calculated. A student's t-test was performed to test if the calculated changes in the observed $\mathrm{VO}_{2} \max$ and the predicted $\mathrm{VO}_{2}$ max were significantly/different. Sata from the control group were used to test the stability of these models.

\section{Results}

Participant characteristics are displayed in Table I (mean \pm standard deviation). Of our 30 participants, two were not included in the analysis as they did not adhere to the assigned intervention. One of the participants' HR at the end of the quarter-mile Rockport Fitness Walking Test was not available in the pre-test due to technical difficulties. 


\section{INSERT TABLE I HERE}

Table II shows the variables used for the new-algorithm, the prediction of the quarter-mile Rockport Fitness Walking Test ${ }^{10}$, and the prediction of the updated-- and new-algorithms developed in this study. The updated-algorithm produced a correlation coefficient $R$ value of 0.41, $(\mathrm{p}=0.015)$. The new-algorithm produced a correlation coefficient $\mathrm{R}$ value of 0.65 , $(\mathrm{p}<0.01)$.

Updated-algorithm:

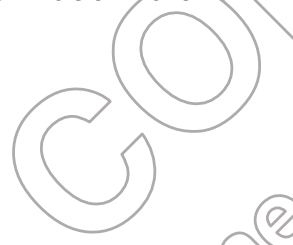

$$
\dot{\mathrm{V}}_{\mathrm{O} 2 \max }=101.0287+1.9435 \cdot \operatorname{Sex}[0=\text { women; } 1=\mathrm{men}]+0.0043
$$

· Body Weight [pounds] - 13.5683 - Walk Time Irninutes] - 0.1625

$\cdot \operatorname{HR}[\mathrm{bpm}]$.

[Eq.3]

New-algorithm:

$\dot{\mathrm{V}}_{\mathrm{O} 2 \max }=73.8854+2.5894 \cdot \mathrm{Sex}[0=$ women; 1 - 0 rien $]-0.1811 \cdot$ Age [years] -

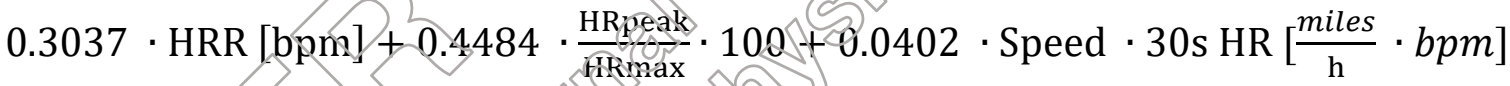

[Eq.4]

\section{INSERT TABLE II HERE}

When comparing the updated-algorithm, new-algorithm, old-algorithm, and the Ebbeling treadmill-based estimations to the observed $\mathrm{VO}_{2} \max$, it was found that the updated- and newalgorithm did not differ significantly from the $\mathrm{VO}_{2} \mathrm{max}$, but the old quarter-mile Rockport Fitness Walking Testwas significantly greater than the observed $\mathrm{VO}_{2}$ max. For the whole group, Ebbeling estimation was not significantly different from the observed $\mathrm{VO}_{2}$ max in the 
pre-test, but it was significantly higher than the observed $\mathrm{VO}_{2} \mathrm{max}$ in the pre-post deltas (see Table III). The Bland-Altman plots for the updated and the new-algorithms can be seen in Figures 2-3.

\section{INSERT FIGURES 2,3}

The differences between the predicted and observed $\mathrm{VO}_{2} \max$ values were compared in order to evaluate the sensitivity of the new-algorithm to changes in the $\mathrm{VO}_{2}$ max after a 4-week training intervention. The training-induced a mean increase in the $\mathrm{VO}_{2} \max$ of the training group of $1.61 \mathrm{ml} \cdot \mathrm{kg}^{-1} \cdot \mathrm{min}^{-1}$. The increase in $\mathrm{VO}_{2} \mathrm{max}$ was significant $(\mathrm{p}=0.02)$. The updatedalgorithm determined a mean $\mathrm{VO}_{2}$ max increase of $0.27 \mathrm{ml} \cdot \mathrm{kg}-1 \cdot \mathrm{min}-\mathrm{I}$, yet this was not significant $(\mathrm{p}=0.65)$. The pre-post deltas of the updated and observed did not significantly differ $(\mathrm{p}=0.22$ ). According to the new-algorithm, the VOAnax increased by $1.67 \mathrm{ml} \cdot \mathrm{kg}-1$ -min-1. The difference between the estimated pre-test and post-test was significant $(p=0.05)$. When comparing the differences in $\mathrm{VO}_{2} \mathrm{max}$ beween the goserved $\mathrm{VO}_{2} \mathrm{max}$ and the newalgorithm predictions, the two values werenot signifieantly different. Table III displays the observed and predicted $\mathrm{VO}_{2}$ max pre-test and post-test values as well as the changes found between the wo during pre-testand post-test for the training and control groups separately. INSER T TABLE III HERE

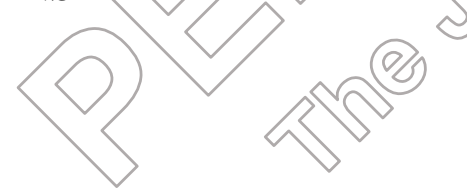

\section{Discussion}

This study provides a new-algorithm which is able to both accurately and precisely predict $\mathrm{VO}_{2}$ max of a general population simply through walking quarter-mile at a brisk pace. This is a reliable submaximal method that generally takes under five minutes and does not require expensive equipment, only a validated heart rate monitor with stop-watch function and a measuring instrument (e.g. tape measure) are required. The results from this study show that the equation developed by George et al. ${ }^{10}$ based on the quarter-mile Rockport Fitness Walking 
Test overestimates $\mathrm{VO}_{2} \max$ values when applied to a population other than college-aged individuals. Although the original Rockport one-mile walking test has been cross-validated and shown to be accurate on a wide range of individuals ${ }^{14-16}$, the quarter-mile Rockport Fitness Walking Test, to our knowledge, has not been cross-validated.

The new-algorithm developed in this study had a 10-fold cross-validation SEE of $5.6 \mathrm{ml} \cdot \mathrm{kg}^{-}$ ${ }^{1} \cdot \mathrm{min}^{-1}$ (around $14 \%$ ). This was found to be more accurate than the existing old-algorithm and the Ebbeling prediction equation, which were found to have SEEs of $21.9 \mathrm{ml} \cdot \mathrm{kg}$ - $1 . \mathrm{min}^{-1}$ (about $58 \%$ ) and $9.95 \mathrm{ml} \cdot \mathrm{kg}^{-1} \cdot \mathrm{min}^{-1}(26 \%)$, respectively. The updated-algoritim based on George et al. 's equation ${ }^{10}$, but with adjusted coefficients to the data of this study showed a drastic improvement in accuracy (down to $18 \%$ relative error).

The old-algorithm based on the quarter-mie Rockpoit Fitness Walking Test was designed to be valid for typical college-aged individuals (age range, $18-29$ years) ${ }^{10}$. The participants in this study ranged in age from 19 years to 46 years. The greater diversity in our sample compared to the sample used to develop the quarter-mite Rockport Fitness Walking Test ${ }^{10}$ may provide an explanation for the inaccuracy abserved when using the old-algorithm in our participants It should be noted that both the quarter-mile Rockport and Ebbeling models were trained (in inachine learning ferms) on different datasets, whereas our updated-algorithm and new-algorithm weretrained on the current dataset. This could potentially explain the overall better performance of our updated and new models. However, in order to demonstrate a greater understanding of the validity of our updated- and new-algorithms we considered 10-fold crossvalidation errors and not algorithm-training errors. Nevertheless, the most plausible explanation of George et al.'s ${ }^{10}$ old-algorithm overestimation is cardiovascular drift ${ }^{17}$. George et al.'s data were collected after participants had already walked three-quarters of a mile, but the data used to develop George et al.'s ${ }^{10}$ algorithm was collected during the final quarter- 
mile. In order to have heart rate data that would accurately predict a person's reaction to briskly walking a quarter-mile, the data should have been extrapolated from the first quarter of a mile. The findings of this study suggest that heart rate is an important variable in predicting $\mathrm{VO}_{2} \mathrm{max}$ due to the direct relationship of $\mathrm{VO}_{2}$ and workload ${ }^{18}$. However, heart rate on its own does carry some prediction errors ${ }^{19}$, suggesting that there is possibly a need for other parameters in predicting $\mathrm{VO}_{2} \max$. Moreover, body composition is not strongly associated with $\mathrm{VO}_{2} \mathrm{max}$ as age increases; since in the elderly, it is less related with lean body mass ${ }^{20}$, which could be another explanation as to why the old-algorithm largely overpredicted $\mathrm{VO}_{2}$ max scores in this study. Yet, the original one-mile Rockport is accurate and relies on the same parameters as the quarter-mile Rockport Fitness Walking Test 9 , 10. This seems to strpport the idea that the main factor that determined the high over-estimation of the ofd atgorith was cardiovascular drift.

As for the Ebbeling test ${ }^{11}$, it has showir to be aceurate and sensitive to $\mathrm{VO}_{2}$ peak changes ${ }^{21}$, ${ }^{22}$, and it has been used previousty to track $\mathrm{MO}_{2} \max$ changes ${ }^{23}$. Our study found the Ebbeling to be accurate in predicting $\mathrm{VO}_{2} \max$ scores durifg the pre-intervention but overall inaccurate in predicting $\mathrm{V}_{2}$ max scores in the post-intervention, indicating a lack of precision and sensitivity,

A precise and sensitive test would be valuable to track changes in the $\mathrm{VO}_{2}$ max should an individual have the desire to increase their fitness through increasing aerobic capacity using an exercise programme. However, it is not always appropriate to maximally exercise an individual, especially those who are particularly unfit or unable to fully exert themselves; thus, a submaximal test that is precise and sensitive is required. This new-algorithm developed could fill that requirement.

A possible limitation of this study and test is the replication of the test, as we were able to use a straight quarter-mile path with no obstructions. This may not always be feasible for testing 
which may pose a difficulty for others who may want to use this test but cannot find the space to do so. Yet, if the space is available a straight quarter-mile is more standardisable.

\section{Conclusion}

The new-algorithm based on a quarter-mile walking test developed in this studyis believed to be an accurate method for estimating $\mathrm{VO}_{2}$ max among an average population between 18 and 50 years of age and demonstrated sensitivity to changes following a four-week exercise intervention. These features of the new-algorithm make it a potentianfy useful model in predicting $\mathrm{VO}_{2} \mathrm{max}$ and monitoring changes in CRF over time. Future research could further

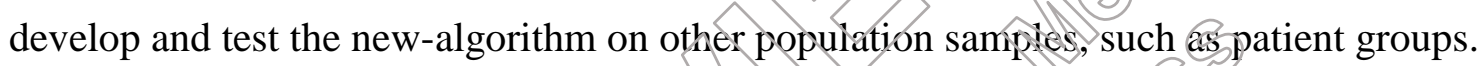




\section{REFERENCES}

1. Lee DC, Artero EG, Sui X, Blair SN. Mortality trends in the general population: the importance of cardiorespiratory fitness. Journal of Psychopharmacology. 2016 Nov;24(4 Suppl):27-35. PubMed PMID: 20923918. Pubmed Central PMCID: 2951585. Epub 2010/10/15. eng.

2. Katzmarzyk PT, Church TS, Blair SN. Cardiorespiratory fitness attenuates the effects of the metabolic syndrome on all-cause and cardiovascular disease mortality in men. Archives of internal medicine. 2004 May 24;164(10):1092-7. PubMed PMID: 15159266. Epub 2004/05/26. eng.

3. Lee CD, Blair SN, Jackson AS. Cardiorespiratory fitness, body composition, and allcause and cardiovascular disease mortality in men. The American journal of clinfeal nutrition. 1999 Mar;69(3):373-80. PubMed PMID: 10075319. Epub 1999/23/13. eng. (a)

4. Papini G, Bonomi AG, Stut W, Kraal JJ, Kemps HMC, Sartor F. Rroof of concept of a 45-second cardiorespiratory fitness self-test for coronary artery disease patients based on accelerometry. PLoS One. 2017;12(9):e0183740, PubMed PMID: 28877186. Pubmed Central PMCID: 5587281. Epub 2017/09/07. eng.

5. Sartor F, Bonato M, Papini G, Bosio A, Mohammed RA, Bongmi AG, et al. A 45Second Self-Test for Cardiorespiratory Fitness: Heart Rate-Based Sstimation in Healthy Individuals. PLoS One. 2016;11(12):e0168154. PubMed PMID: 29659935. Pubmed Central PMCID: 5154562 have the following competing interests: F.S and A.G.B. work for Philips Research; G.P. was doing an internship at Philips Researen during his contribution in this work. A.B. works for Mapei Sport. All other amithors have no conflict of interest. This does not alter our adherence to PLOS ONE policies om sharing data and materials. Epub 2016/12/14. eng.

6. Sartor F, Vernille G, de Morree HM, Bonomi AG, La Torre A, Kubis HP, et al. Estimation of maximal oxygen uptake via submaximal exercise testing in sports, clinical, and home settings Sports Medicine 2013;43(9):865-73.

7. Bassey EJ, Fentem PH, MilacDonald IC, Scriven PM. Self-paced walking as a method for exereise testing in elân and young men. Clinical Sciences Molecular Medicine. 1976 Des,51(6):609-12. PubMed PMID: 1070426. Epub 1976/12/01. eng.

8. Noonan K Bean E. Submaximal exercise testing: clinical application and interpretation. Physical therapy. 2000 Aug;80(8):782-807. PubMed PMID: 10911416. Epub 2000/07/27. eng.

9. Kline GM, Porcari JP, Hintermeister R, Freedson PS, Ward A, McCarron RF, et al. Estimation of VO2max from a one-mile track walk, gender, age, and body weight. Medicine \& Science in Sports \& Exercise. 1987;19(3):253-9.

10. George JD, Fellingham GW, Fisher AG. A modified version of the Rockport Fitness Walking Test for college men and women. Research quarterly for exercise and sport. 1998;69(2):205-9.

11. Ebbeling CB, Ward A, Puleo EM, Widrick J, Rippe JM. Development of a single-stage submaximal treadmill walking test. Medicine \& Science in Sports \& Exercise. 1991;23(8):966-73.

12. Thompson WR, Gordon NF, Pescatello LS, ACSM. ACSM's guidelines for exercise testing and prescription. 8th ed. Philadelphia: Lippincott Williams \& Wilkins; 2010.

13. Tanaka H, Monahan KD, Seals DR. Age-predicted maximal heart rate revisited. J Am Coll Cardiol. 2001 Jan;37(1):153-6. PubMed PMID: 11153730. Epub 2001/01/12. eng. 
14. Fenstermaker KL, Plowman SA, Looney MA. Validation of the Rockport Fitness Walking Test in females 65 years and older. Research quarterly for exercise and sport. 1992 Sep;63(3):322-7. PubMed PMID: 1513964. Epub 1992/09/01. eng.

15. Greenhalgh HA, George JD, Hager RL. Cross-validation of a quarter-mile walk test using two VO2max regression models. Measurement in Physical Education and Exercise Science. 2001 5(3):139-51.

16. Rintala P, McCubbin JA, Downs SB, Fox SD. Cross validation of the 1-mille walking test for men with mental retardation. Medicine \& Science in Sports \& Exercise. 1997 Jan;29(1):133-7. PubMed PMID: 9000166. Epub 1997/01/01. eng.

17. Shaffrath JD, Adams WC. Effects of airflow and work load on cardiovascular drift and skin blood flow. Journal of applied physiology: respiratory, environmental and exercise physiology. 1984 May;56(5):1411-7. PubMed PMID: 6725094. Epub 1984/05/101. eng.

18. Astrand PO, Ryhming I. A nomogram for calculation of aerobic capacity (physical fitness) from pulse rate during sub-maximal work. Journal of applied physiology. 1954;7(2):218-21.

19. Davies CT. Limitations to the prediction of maximum exy gen intare from cardiac frequency measurements. Journal of applied physiology 1968 May;24(5).700-6. PubMed PMID: 5653154. Epub 1968/05/01. eng.

20. Davies CT. Maximum aerobic power/in relation to bodsocomposition in healthy, sedentary adults. Human Biology. 1972;44(1):127,39.

21. George JD, Paul SL, Hyde A, Bradshaw DI, Vehrs PR. Hager R. et al. Prediction of maximum oxygen uptake using both exercise and non-exereise data Mreasurement in Physical Education and Exercise Science. 2009;13(1):1-12.

22. Mitros M, Gabriel KP, Ainsworth B, Le - C, Hermann S, Campbell K, et al. Comprehensive evaluation of a single-stage submaximas treadmill walking protocol in healthy, middle-aged women. European journabor applied physiology. 2011 Jan;111(1):4756. PubMed PMID: 20809230 Epub 2010/09/03. eng?0

23. Rospo G, Valsecchi V, Bonomi AGThonassen IW, van Dantzig S, La Torre A, et al. Cardiorespiratory Jmprevements Achieved by American College of Sports Medicine's Exercise Prescription Implemented on a Mobile App. JMIR Mhealth Uhealth. 2016 Jun 23;4(2):e77 PubMed PMID: 27339153. Pubmed Central PMCID: 4937178. Epub 2016/06/25. eng.

\section{NOTES}

Conflicts of interest.-

Alberto G. Bonomi and Francesco Sartor work for Philips Electronics B.V.. Chandrie Cook and Gabriele B. Papini were conducting an internship at Philips Research when the study was conducted. All other authors have no conflict of interest.

\section{Funding.-}

No additional funding was received for this study. 
Page 18 of 24

1

2

\section{Authors' contributions.-}

Gabriele B Papini has processed, analyzed the data and created the prediction models, and co-drafted the manuscript. Chandrie Cook has collected the data, analyzed the data, and drafted the first version of the manuscript. Hans-Peter Kubis has co-designed the study, critically evaluated the results and revised the manuscript. Alberto G. Bonomi has co-designed the study, critically evaluated the results and revised the manuscript. Courtney J. Lightfoot has critically revised and proofread the manuscript. Francesco Sartor was the principal investigator, and has organized the study, collected data, analyzed data critically evaluated the results, co-drafted the manuscript.

\section{Acknowledgements. $-\mathbf{-}$}

The authors would like to thank Leonie van den Heuvel, Gianluca Rospo, Rob van der Straaten and Viola Valsecchi for their help during the datachllection.

Table I.- Descriptive characteristics and data from the quapter-srile walk test of all participants

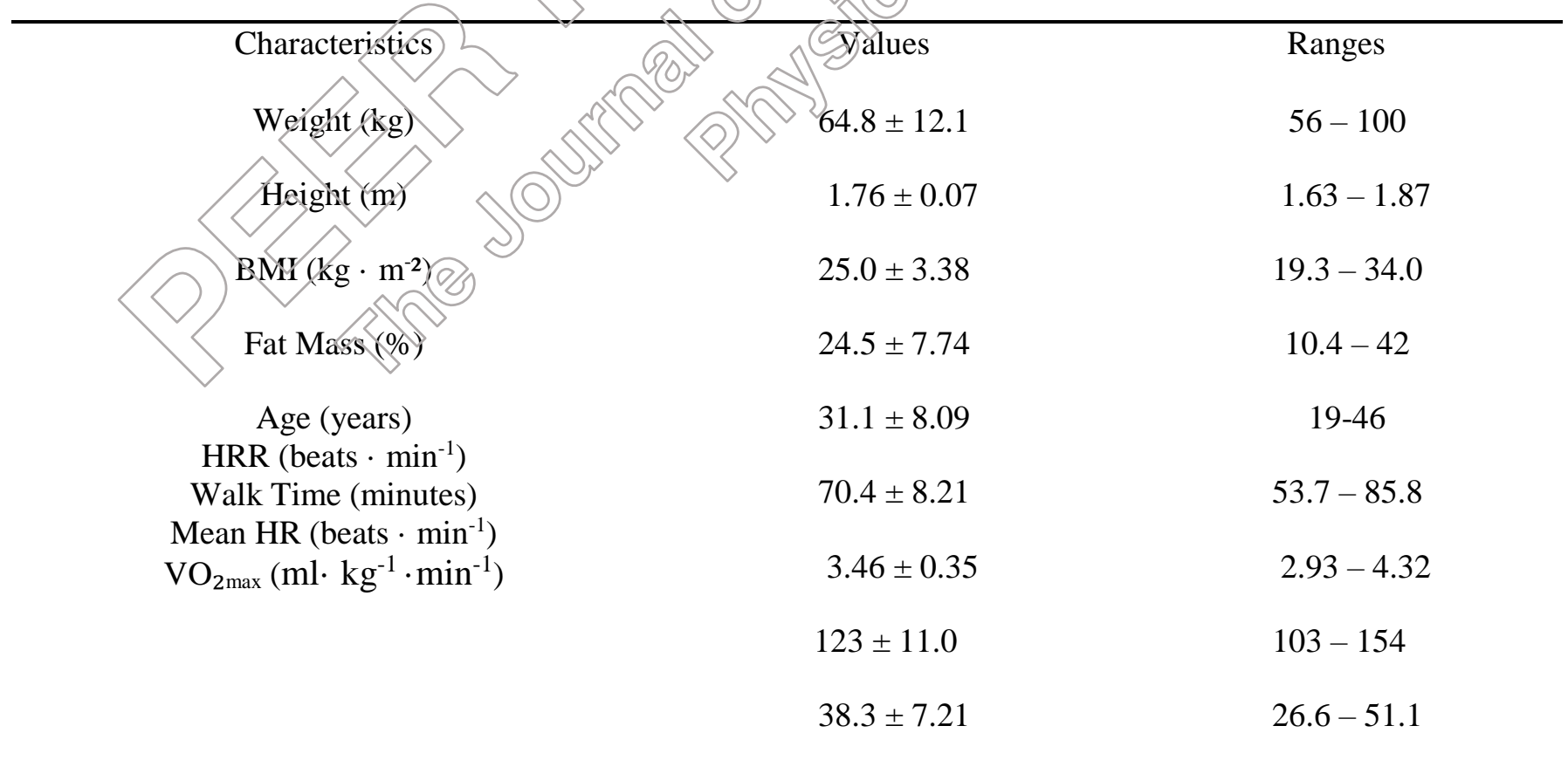

Means \pm standard deviation 


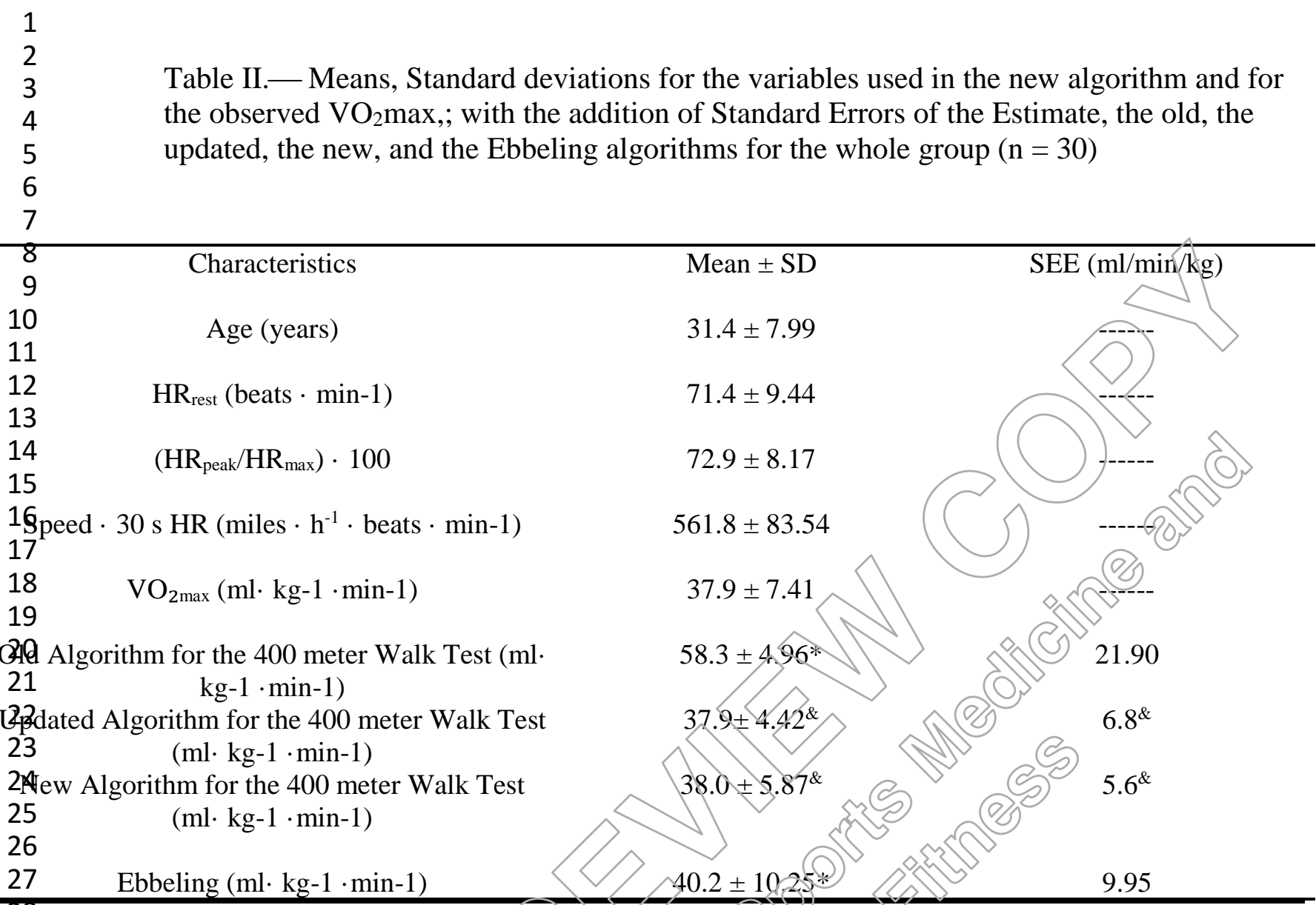

*2:Phe old quarter-mile Rockport Fitness Waiking Test algorithm aid the Ebbeling algorithm were significantly higher than the observed $\mathrm{VO}_{2 \max }(p<0.05)$ 30 -fold cross-validation errors 31

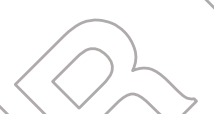

Table III.- Pre-test and post-test values of the observed $\mathrm{VO}_{2}$ max, the Old-Algorithm, the Updated-Algorithm, and the Nen-Algorithm for the quarter-mile (400 meters) Walk Test predicted $\mathrm{VO}_{2} \mathrm{max}$, and the Eb beling predicted $\mathrm{VO}_{2}$ max in both training and control groups. Changes in $\mathrm{VO}_{2}$ max between the pre-test and post-test

\begin{tabular}{|c|c|c|c|c|c|}
\hline \multicolumn{3}{|c|}{ Training } & \multicolumn{3}{|c|}{ Control } \\
\hline Pretest & Posttest & $\begin{array}{l}\Delta \text { Posttest- } \\
\text { Pretest }\end{array}$ & Pretest & Posttest & $\begin{array}{c}\Delta \text { Posttest- } \\
\text { Pretest }\end{array}$ \\
\hline $7.8 \pm 7.25$ & $39.4 \pm 6.98$ & $1.61 \pm 2.84$ & $34.8 \pm 7.43$ & $35.8 \pm 7.47$ & $0.92 \pm 1.63$ \\
\hline
\end{tabular}


Page 20 of 24

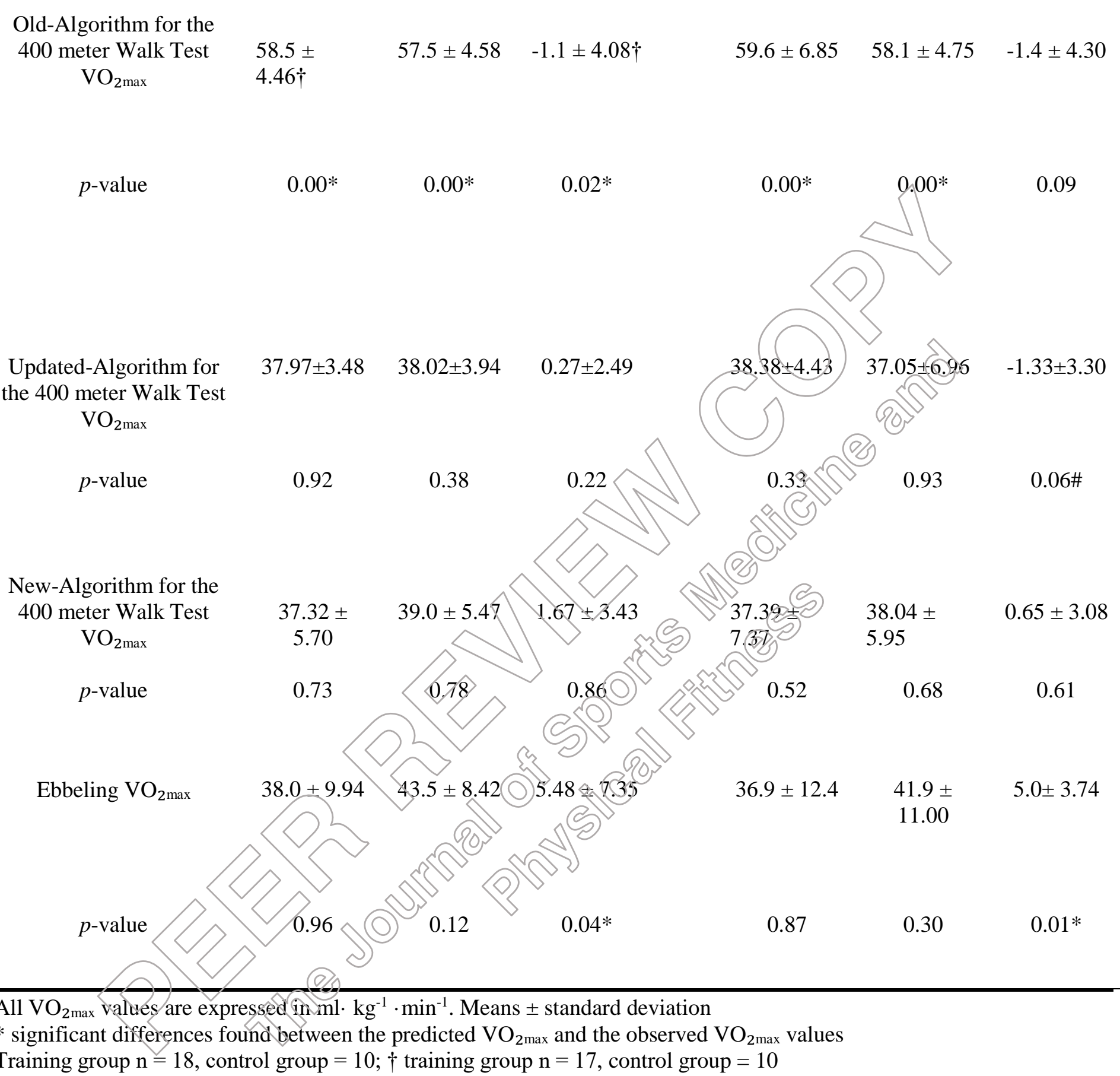

Old-Algorithm for the

\section{$40^{*}$ significant differences found between the predicted $\mathrm{VO}_{2 \max }$ and the observed $\mathrm{VO}_{2 \max }$ values}

41 Training group $n=18$, control group $=10 ; \uparrow$ training group $n=17$, control group $=10$

\section{TITLES OF FIGURES}

Figure 1.- Displays the testing schedule used during the study. Participants came in week 0 for the pretests. Weeks 1-4 included the intervention for those in the training group. During week 3 the mid submaximal test was performed on both groups. During week 5 the posttests were performed.

Figure 2.- Scatter plot and Bland-Altman plot of the updated-algorithm based on quartermile Rockport Fitness Walking Test as developed by George et al. (see text for reference). 
Figure 3.- Scatter plot and Bland-Altman plot of the new-algorithm based new features extracted from the quarter-mile Rockport Fitness Walking Test (see text for more details).

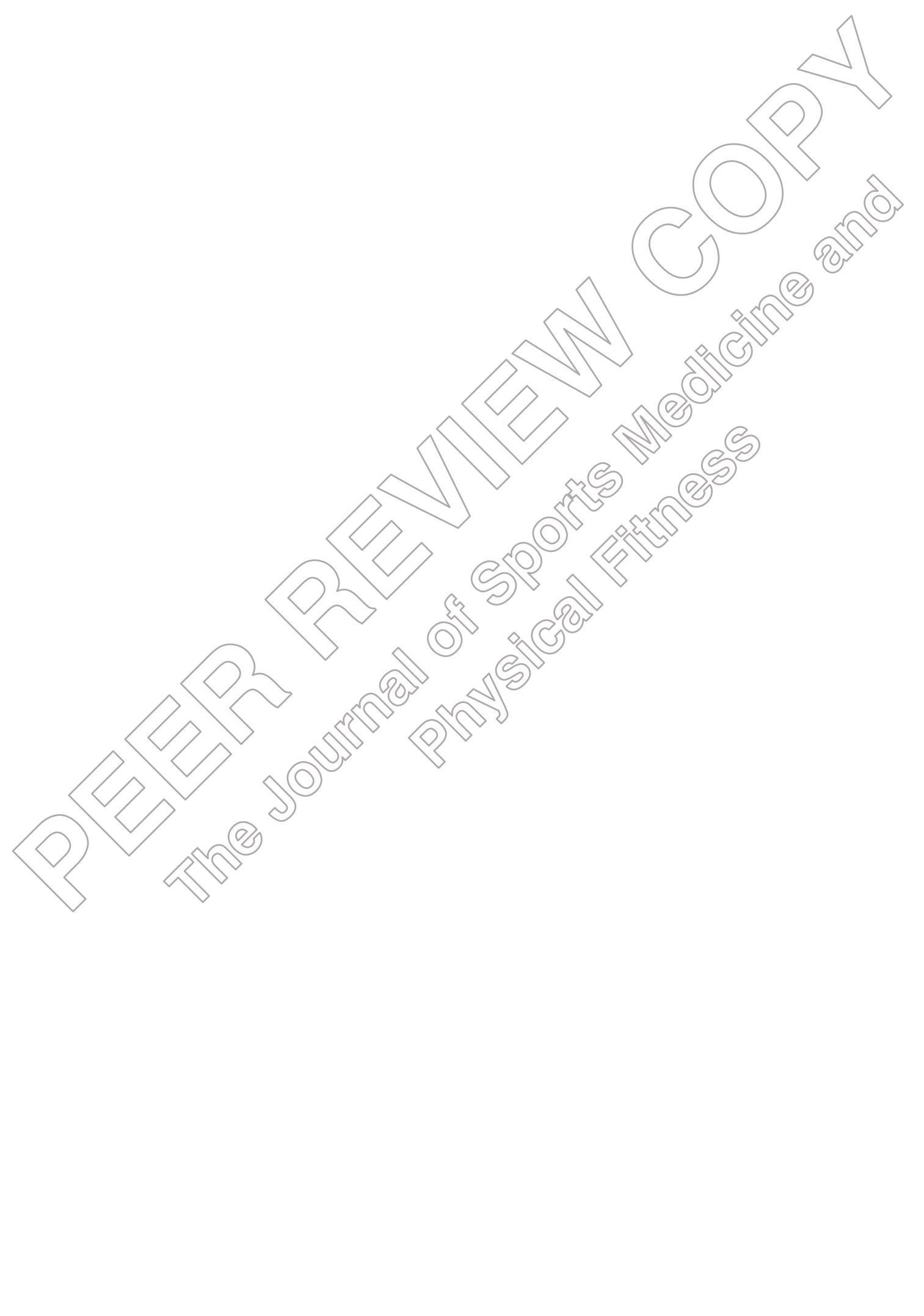


Page 22 of 24

1
2
3
4
5
6
7
8
9
10
11
12
13
14
15
16
17
18
19
20
21
22
23
24
25
26
27
28
29
30
31
32
33
34
35
36
37
53
38
39
40
41
42
43
44
45
46
47
59
51


Page 23 of 24

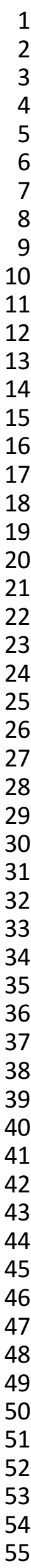

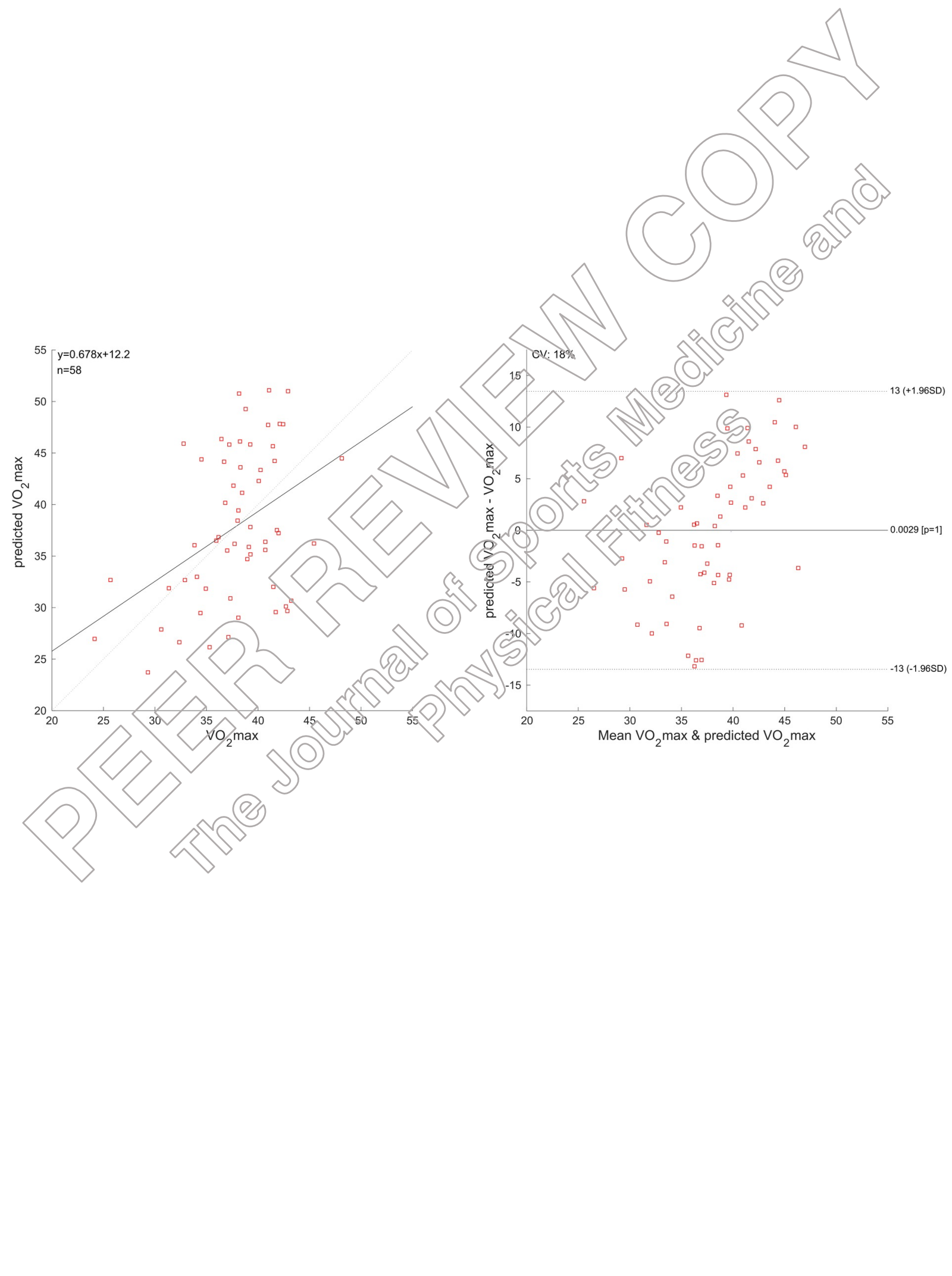


Page 24 of 24
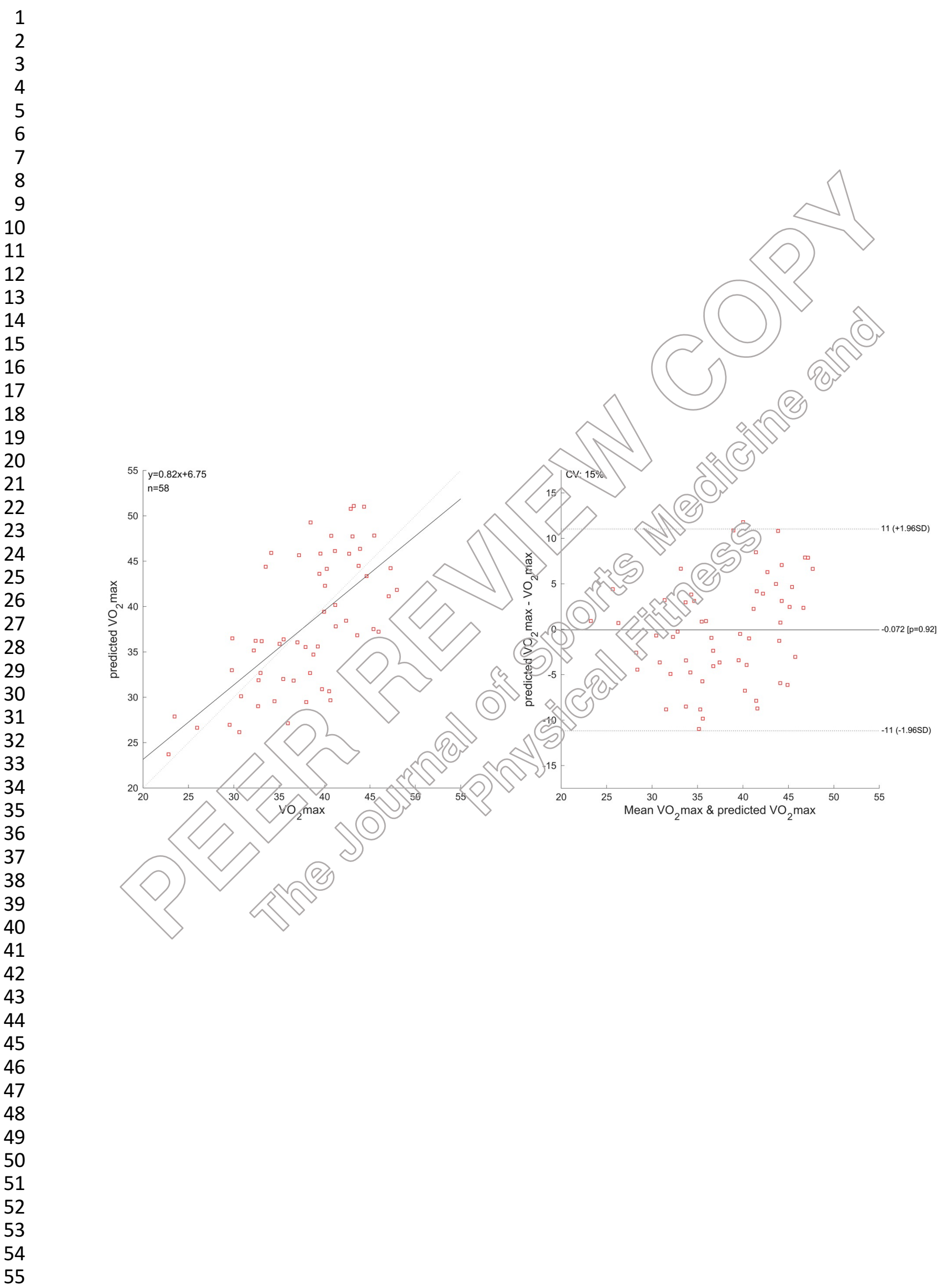